\title{
Genetic polymorphisms of DNA double-strand break repair pathway genes and glioma susceptibility
}

Peng Zhao ${ }^{1^{*+}}$, Peng Zou ${ }^{1+}$, Lin Zhao ${ }^{1}$, Wei Yan ${ }^{2}$, Chunsheng Kang ${ }^{3}$, Tao Jiang ${ }^{2}$ and Yongping You ${ }^{1 *}$

\begin{abstract}
Background: Genetic variations in DNA double-strand break repair genes can influence the ability of a cell to repair damaged DNA and alter an individual's susceptibility to cancer. We studied whether polymorphisms in DNA double-strand break repair genes are associated with an increased risk of glioma development.

Methods: We genotyped 10 potentially functional single nucleotide polymorphisms (SNPs) in 7 DNA double-strand break repair pathway genes (XRCC3, BRCA2, RAG1, XRCC5, LIG4, XRCC4 and ATM) in a case-control study including 384 glioma patients and 384 cancer-free controls in a Chinese Han population. Genotypes were determined using the OpenArray platform.

Results: In the single-locus analysis there was a significant association between gliomas and the L/G4 rs1805388 (Ex2 +54C>T, Thr9lle) TT genotype (adjusted OR, 3.27; 95\% Cl, 1.87-5.71), as well as the TC genotype (adjusted OR, 1.62; $95 \% \mathrm{Cl}, 1.20-2.18$ ). We also found that the homozygous variant genotype (GG) of XRCC4 rs 1805377 (IVS7-1A>G, splice-site) was associated with a significantly increased risk of gliomas (OR, 1.77; 95\% Cl, 1.12-2.80). Interestingly, we detected a significant additive and multiplicative interaction effect between the LIG4 rs1805388 and XRCC4 rs 1805377 polymorphisms with an increasing risk of gliomas. When we stratified our analysis by smoking status, LIG4 rs 1805388 was associated with an increased glioma risk among smokers.
\end{abstract}

Conclusions: These results indicate for the first time that LIG4 rs1805388 and XRCC4 rs1805377, alone or in combination, are associated with a risk of gliomas.

Keywords: DNA double-strand breaks (DSBs), Single nucleotide polymorphisms (SNPs), Glioma, Susceptibility

\section{Background}

Gliomas are the most common type of primary intracerebral neoplasm in China as well as in the West, and comprise more than $40 \%$ of primary brain tumors in humans [1-3]. Although the etiology of gliomas remains unclear, exposure to ionizing radiation (IR) and genetic alterations are unequivocally associated with an increased risk of gliomas [4].

DNA double-strand breaks (DSBs) can be generated during $\mathrm{V}(\mathrm{D})$ J recombination, class-switch recombination at the immunoglobulin heavy chain (IgH) locus or meiosis and result from a variety of factors including

\footnotetext{
* Correspondence: zhaopeng@njmu.edu.cn; yypl3@sohu.com

${ }^{\dagger}$ Equal contributors

'Department of Neurosurgery, the First Affiliated Hospital of Nanjing Medical University, Nanjing 210029, China

Full list of author information is available at the end of the article
}

ionizing radiation and reactive oxygen species [5]. Inadequacy or defects in DSB repair can lead to large-scale loss of genetic information and can have disastrous consequences such as genomic instability, immunodeficiency, radiosensitivity, cell death and oncogenic transformation [6,7]. DSBs are sensed by the MRN (MRE11, RAD50, and NBS1) complex, which catalyzes activation of ATM [8,9]. Two major pathways have evolved in mammalian cells to repair DSBs: non-homologous endjoining (NHEJ) and homologous recombination (HR). The central components of the NHEJ pathway are Ku70 (XRCC6), Ku80 (XRCC5), DNA-dependent protein kinase catalytic subunit (DNA-PKcs), XRCC4 and DNA ligase IV (LIG4) proteins [10]. RAD51 interacts with other important repair proteins, including BRCA1, BRCA2, $\mathrm{XRCC} 2$, and XRCC3 and plays a central role in the HR

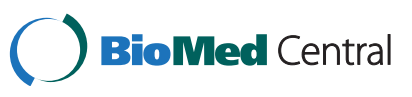


activation through the use of sister-chromatid sequences as a template for precise repair [11].

Recent evidence suggests that several single nucleotide polymorphisms (SNPs) in the DSB repair pathway genes may be prognostic biomarkers for GBM survival and modulate gamma-radiation-induced mutagen sensitivity in glioma patients $[12,13]$. Genetic variants in DSB repair pathway genes have been extensively studied in multiple cancers. However, few studies have specifically identified any association between genetic variations in the DSB repair pathway genes and the risk of gliomas. Here we investigate the role of 10 potential SNPs in XRCC3, BRCA2, RAG1, XRCC5, LIG4, XRCC4 and ATM in the development of gliomas, and further evaluate their gene-gene and gene-environment interactions in the development of glioma.

\section{Methods}

\section{Study population}

The study was approved by the Ethics Review Board of Nanjing Medical University. All studies involving human subjects were conducted under full compliance with government policies and the Helsinki Declaration. From 2005 to 2010, a total of 447 patients with histopathologically confirmed gliomas were recruited from the Department of Neurosurgery of Jiangsu Province Hospital (the First Affiliated Hospital of Nanjing Medical University) and Beijing Tiantan Hospital Neurosurgery Center (BTHNC). The tumors were graded according to the World Health Organization (WHO) classification [3]. A total of $408(87 \%)$ patients agreed to the study. The 400 healthy control subjects without a history of cancer were recruited from health examination clinics at these hospitals concurrent with the recruitment of glioma patients. The control subjects were frequently matched to cases by age and sex. All cases and controls in this study were genetically unrelated ethnic Han Chinese. All participants completed an informed consent in accordance with the requirements of the institutional review board of each participating institution and a structured questionnaire to obtain detailed information on diet, weight, height, smoking habits and drinking status. After the interview a blood sample $(5 \mathrm{ml})$ was collected from each study subject, gathered into heparinized tubes and stored at $-70^{\circ} \mathrm{C}$ until used for DNA extraction and genotyping. Finally, 384 glioma patients and 384 cancer-free controls whose DNA samples were available and adequate were included in our work.

\section{SNP selection and genotyping}

Potential functional SNPs within each gene were identified through an extensive mining of the databases of the International HapMap Project and dbSNP. As a result, 10 SNPs in the coding sequence, promoter, splice sites, and $5^{\prime}$ or
$3^{\prime}$-UTRs with a minor allele frequency (MAF) $\geq 0.05$ in the general Han Chinese population were selected.

Genomic DNA was isolated from leukocyte pellets of venous blood by proteinase $\mathrm{K}$ digestion and phenolchloroform extraction. Genotyping was performed using the OpenArray platform (Applied Biosystems, Foster City, California, USA). This platform employs a chipbased TaqMan genotyping technology. Sequences of primers and probes are available on request. Genotyping was conducted according to the manufacturer's standard protocols, and genotype calls were made by OpenArray SNP Genotyping Analysis Software V.1.0.3. To ensure quality control, genotyping was performed without the knowledge of individual case-control status. We randomly selected $5 \%$ of the samples to be genotyped again by different investigators and the reproducibility rate was $100 \%$. To validate the genotyping results, selected PCR-amplified DNA samples $(\mathrm{n}=2$, for each genotype) were confirmed by DNA sequencing, and these results were found to be $100 \%$ concordant.

\section{Statistical analysis}

Demographic variables between cases and controls were compared using Student's $t$ test (age and pack-years) for continuous variables and the $\chi^{2}$ test for categorical variables (gender, smoking and drinking status). The HardyWeinberg equilibrium (HWE) was evaluated in control subjects using a goodness-of-fit $X^{2}$ test with 1 degree of freedom. The effect of each SNP on glioma risk was estimated as an odds ratio and 95\% confidence intervals (95\% CI) by unconditional logistic regression adjusted by age, gender, smoking and drinking status. A score test of linear trend was conducted for each SNP using a three-level ordinal variable. To minimize false positive results generated from the multiple statistical tests used in our analysis, we applied a false discovery rate (FDR) method to the $P$ values for trend [14]. To evaluate effect modification by smoking, subgroup analyses were also performed for LIG4 rs1805388 and XRCC4 rs1805377 polymorphisms. A more-than-multiplicative gene-gene or gene-environment interaction was evaluated using logistic regression analysis. When the test for multiplicative interaction was not rejected, further test for an additive interaction was done by a bootstrapping test of goodness-of-fit of the null hypothesis, for no departure from the additive model compared to an alternative hypothesis, and for a departure from an additive model by using Stata software (version 8.2; StataCorp LP). All the other statistical analyses were performed with SAS 9.1.3 software (SAS Institute).

\section{Results}

\section{Sample characteristics}

The distribution of demographic characteristics of the 384 cancer cases and 384 cancer-free controls available 
for this analysis are summarized in Table 1. Cases and controls were well matched on age $(P=0.277)$, gender $(P=0.715)$, smoking status $(P=0.465)$ and drinking status $(P=0.222)$, suggesting that our frequency matching of the demographic characteristics was satisfactory.

\section{Individual SNP association analysis}

Primary information of the 10 functional SNPs found in the Chinese population in the dbSNP database is presented in Table 2. All tested SNPs were in agreement with Hardy-Weinberg equilibrium in the control subjects $(p>0.05)$.

In the multivariate logistic regression models (Table 3), each of the variant genotypes of LIG4 rs1805388 was associated with a significantly increased risk of gliomas compared to the wild-type CC genotype (adjusted OR, 1.62; 95\% CI, 1.20-2.18 for CT and adjusted OR, 3.27; 95\% CI, 1.87-5.71 for TT, respectively). Similarly, compared with the common homozygous genotype, carriers with XRCC4 rs1805377 homozygous variant genotype showed a significantly increased risk of gliomas (adjusted OR, 1.77; 95\% CI, 1.12-2.80 for GG). Furthermore, the association for allele variants were dose dependent for each locus (Trend test: $P<0.001$ and $P=0.030$ for rs1805388 and rs1805377, respectively).

Table 1 Distribution of selected host characteristics by case-control status in Chinese

\begin{tabular}{|c|c|c|c|}
\hline Variables & Case $(n=384)$ & Control $(n=384)$ & $P^{b}$ \\
\hline Age, y (mean $\pm S D)$ & $62.4 \pm 10.8$ & $61.5 \pm 12.1$ & 0.277 \\
\hline \multicolumn{4}{|l|}{ Gender, no. (\%) } \\
\hline Male & $222(57.8)$ & $217(56.5)$ & 0.715 \\
\hline Female & $162(42.2)$ & $167(43.5)$ & \\
\hline \multicolumn{4}{|l|}{ Smoking status, no. (\%) } \\
\hline No & $228(59.4)$ & $218(56.8)$ & 0.465 \\
\hline Yes & $156(40.6)$ & $166(43.2)$ & \\
\hline Pack-years (mean $\pm \mathrm{SD})^{a}$ & $32.7 \pm 25.1$ & $30.3 \pm 27.7$ & 0.209 \\
\hline \multicolumn{4}{|l|}{ Drinking status, no. (\%) } \\
\hline No & $288(75.0)$ & $273(71.1)$ & 0.222 \\
\hline Yes & $96(25.0)$ & $111(28.9)$ & \\
\hline \multicolumn{4}{|l|}{ WHO grade, no. (\%) } \\
\hline WHOI & $41(10.7)$ & & \\
\hline WHO II & $176(45.8)$ & & \\
\hline WHO III & $86(22.4)$ & & \\
\hline WHO IV & $81(21.1)$ & & \\
\hline
\end{tabular}

${ }^{\mathrm{a} A m o n g}$ ever smokers.

${ }^{\mathrm{b}} \mathrm{P}$ values were derived from the $x^{2}$ test for categorical variables (gender, smoking and drinking status) and t test for continuous variables (age and pack-years).

\section{Interaction between smoking and genetic factors}

We further evaluated the interaction between the LIG4 rs1805388 and XRCC4 rs1805377 polymorphisms and tobacco smoking with respect to the risk of gliomas. We detected a significant additive $\left(P_{\text {interaction }}=0.013\right)$ and multiplicative interaction $\left(P_{\text {interaction }}=0.046\right)$ effect between LIG4 rs1805388 and tobacco smoking for the development of gliomas. Compared with never-smokers carrying the wild-type genotype of LIG4 rs1805388, those ever-smokers with variant-containing genotype of LIG4 rs1805388 polymorphism had a significantly increased risk to develop gliomas (adjusted OR, 1.67; 95\% CI, 1.11-2.50) (Table 4).

\section{Combined analysis of multiple SNPs}

The LIG4-XRCC4 complex plays a fundamental role in DNA non-homologous end-joining and is present in all eukaryotes. It has been demonstrated that XRCC4 can stimulate LIG4 activity and is required to stabilize LIG4. Thus, we estimated the combined effect of LIG4 and XRCC4 genes on glioma risk. As shown in Table 5, 35.4\% of the cases and $19.3 \%$ of the controls had variant genotypes at both loci (LIG4 rs1805388 CT+TT and XRCC4 rs1805377 AG+GG). In comparison with the reference combination of LIG4 rs1805388 CC and XRCC4 rs1805377 AA, the combination of the LIG4 rs1805388 CT+TT genotype together with XRCC4 rs1805377 AG+GG genotype was found to be significantly associated with glioma (adjusted OR, 2.22; 95\% CI, 1.49-3.30). Furthermore, significant more-than-multiplicative (0.005) and more-than additive (0.009) gene-gene interactions of these two loci (LIG4 rs1805388 CT+TT and XRCC4 rs1805377 $\mathrm{AG}+\mathrm{GG}$ ) were found in relation to the risk of gliomas.

\section{Discussion}

Accumulating evidence demonstrates that the DSB repair pathway plays a critical role in repairing doublestrand breaks caused by a variety of exposures. Although genetic variants in DSB repair pathway genes are considered as potential risk factors for various cancers, less evidence exists as to the potential role of the DSB repair pathway genes polymorphisms on glioma susceptibility. To our knowledge, this study is the first to provide a comprehensive evaluation of the relationship between polymorphisms in both NHEJ and HR pathway genes and susceptibility to gliomas. On the basis of our analysis of 384 controls and 384 glioma patients, we observed that one splice-site SNP in XRCC4 (rs1805377, IVS7-1A $>$ G, splice-site) and one non-synonymous SNP in LIG4 (rs1805388, Ex2 +54C>T, Thr9Ile) are associated with the increased susceptibility to gliomas in a Chinese population.

Previous researches on the function of the XRCC4 rs1805377 and LIG4 rs1805388 polymorphisms have 
Table 2 Primary information for 7 genotyped SNPs in DNA repair genes

\begin{tabular}{lccc}
\hline Genotyped SNPs & $\begin{array}{c}\text { Location/or amino acid } \\
\text { change }\end{array}$ & $\begin{array}{c}\text { MAF for Chinese in } \\
\text { database }\end{array}$ & $\begin{array}{c}\boldsymbol{P} \text { value for HWE } \\
\text { test }\end{array}$ \\
\hline XRCC3: rs861539 C>T & nsSNP/ T241M & 0.067 & 0.165 \\
XRCC3: rs1799794 G>A & 5' UTR & 0.478 & 0.271 \\
XRCC3: rs1799796 A>T & nsSNP/ A17893G & 0.289 & 0.406 \\
BRCA2: rs1799943 G>A & Promoter & 0.279 & 0.722 \\
BRCA2: rs15869 A>C & 3' UTR & 0.244 & 0.375 \\
RAG1: rs2227973 G>A & nsSNP/ R820K & 0.465 & 0.586 \\
XRCC5: rs1051685 A>G & 3' UTR & 0.067 & 0.808 \\
LIG4: rs1805388 C>T & nsSNP/T9l & 0.261 & 0.659 \\
XRCC4: rs1805377 A>G & Splice Site & 0.300 & 0.454 \\
ATM: rs189037 G>A & Promoter & 0.389 & 0.070 \\
\hline
\end{tabular}

MAF, minor allele frequency; HWE, Hardy-Weinberg equilibrium.

${ }^{a}$ Minor allele frequency in the Chinese (CHB, Han Chinese in Beijing, China) population, as reported in dbSNP database.

been informative in understanding the potential roles of these two polymorphisms in the development of gliomas. The LIG4 rs1805388 polymorphism results in a nonsynonymous amino acid change from threonine to isoleucine at the N-terminal of the LIG4 protein that is essential for its activity [15]. Two linked polymorphisms rs1806389 (T9I) and rs1805388 (A3V) in the N-terminal of LIG4 mildly but reproducibly reduce adenylation and ligation activities (2-3fold) [16] and increase the hydrophobic nature of this region of the protein [17]. The XRCC4 rs1805377 polymorphism in intron 7 may have functional significance since the nucleotide change potentially abolishes an acceptor splice site at exon $8[18,19]$.

Gene-gene interaction was also studied since XRCC4 and LIG4 proteins form a tight and specific complex that catalyzes ligation of processed DNA ends. Although LIG4 interacts with the coiled-coil region of human XRCC4 via the region that lies between the two Cterminal BRCT domains [15,20,21], the combined analysis of multiple SNPs revealed that LIG4 rs1805388 which causes a nonsynonymous amino acid change at the N-terminal of the LIG4 protein and XRCC4 rs1805377 interacted to modulate the risk of gliomas as a joint effect. Tseng et al. [22] performed a gene-gene interaction analysis which revealed that polymorphisms in the XRCC4 (rs1805377) and LIG4 (rs1805388) genes interacted to modulate the risk of lung cancer (adjusted OR, 8.75) and demonstrated that LIG4 rs1805388 and XRCC4 rs1805377 polymorphisms are linked significantly with high fractional allelic loss (FAL), an indicator of genomic instability. Taken together, considering the functional relevance of these two proteins, an individual SNP or combinations of these two SNPs may change the activity of the LIG4-XRCC4 complex and pose a substantial influence on the development of gliomas.

Overwhelming evidence indicates that our findings are biologically plausible. NHEJ is a multistep process initiated by the XRCC5/XRCC6 dimer (also known as $\mathrm{Ku} 80 / \mathrm{Ku} 70$ ) which immediately binds to both broken ends of DNA and recruits the DNA-dependent protein kinase catalytic subunit (DNA-PKcs) forming the trimeric DNA-PK holoenzyme [23,24]. Finally, the LIG4XRCC4 complex in vivo carries out the ligation step to complete repair [10]. XRCC4 serves as a multipurpose partner for the LIG4 protein, facilitating LIG4 stability and stimulating LIG4 adenylation [21]. Consistent with the need for effective repair of DSBs by NHEJ, XRCC4or LIG4-deficient mouse fibroblasts exhibit marked sensitivity to ionizing radiation, growth defects and premature senescence $[25,26]$. The deficiency of DSB repair has led to significant improvements in radiation sensitization of gliomas [27]. Furthermore, XRCC4 or LIG4 null mice die in late embryogenesis accompanied by defective lymphogenesis and massive apoptotic cell death of newly generated postmitotic neurons [28,29]. Many studies in the past have shown that the deficiency of LIG4 or XRCC4 in animals can lead to increased rates of neoplastic transformation. Although loss of p53 expression rescues neuronal death and embryonic lethality, XRCC4 or $L I G 4 / p 53$ double-null mice routinely succumbed to RAG-dependent pro-B lymphomas with translocations/amplifications of $\mathrm{c}-\mathrm{myc}$ and $\mathrm{IgH}$ loci $[28,29]$. Nijnik et al. found that LIG4 ${ }^{\mathrm{Y} 28 \mathrm{C}}$ mice (a mouse model for human LIG4 syndrome) exhibit multiple defects in lymphocyte development and a hypomorphic LIG4 mutation can confer strong predisposition to lymphoid malignancies [30]. In addition to tumors of the immune system, Sharpless et al. demonstrated that LIG4 haploinsufficiency with decreased NHEJ activity contributes to development of soft tissue sarcomas that possess clonal amplifications, deletions and translocations [31]. A defective DNA double-strand break repair pathway in the nervous system can also lead to brain tumors. Lee et al. demonstrated that LIG4/p53 double- 
Table 3 Associations between candidate genes and glioma risk

\begin{tabular}{|c|c|c|c|c|c|}
\hline Genotype & Cases, n(\%) & Controls, n(\%) & OR $(95 \% \mathrm{Cl})^{\mathrm{a}}$ & $P_{\text {trend }}{ }^{\mathrm{b}}$ & $P$ value for HWE test \\
\hline \multicolumn{6}{|c|}{ XRCC3: rs861539 (T241M) } \\
\hline $\mathrm{CC}$ & $336(87.5)$ & $340(88.5)$ & 1.00 & 0.835 & 0.165 \\
\hline CT & $47(12.2)$ & $41(10.7)$ & $1.15(0.73-1.79)$ & & \\
\hline$\pi$ & $1(0.3)$ & $3(0.8)$ & $0.33(0.03-3.22)$ & & \\
\hline \multicolumn{6}{|c|}{ XRCC3: rs1799794 (-4541G>A) } \\
\hline GG & $100(26.0)$ & $108(28.1)$ & 1.00 & 0.838 & 0.271 \\
\hline GA & $201(52.4)$ & $181(47.1)$ & $1.09(0.78-1.53)$ & & \\
\hline $\mathrm{AA}$ & $83(21.6)$ & $95(24.8)$ & $0.86(0.57-1.28)$ & & \\
\hline \multicolumn{6}{|c|}{ XRCC3: rs1799796 (A17893G) } \\
\hline AA & $178(46.4)$ & $171(44.5)$ & 1.00 & 0.231 & 0.406 \\
\hline AT & $173(45.0)$ & $165(43.0)$ & $0.97(0.72-1.31)$ & & \\
\hline$\Pi$ & $33(8.6)$ & $48(12.5)$ & $0.64(0.39-1.04)$ & & \\
\hline \multicolumn{6}{|c|}{ BRCA2: rs1799943 (-26G>A) } \\
\hline GG & $158(41.2)$ & $180(46.9)$ & 1.00 & 0.149 & 0.722 \\
\hline GA & $186(48.4)$ & $168(43.7)$ & $1.22(0.90-1.64)$ & & \\
\hline $\mathrm{AA}$ & $40(10.4)$ & $36(9.4)$ & $1.22(0.74-2.01)$ & & \\
\hline \multicolumn{6}{|c|}{ BRCA2: rs15869 (3' UTR) } \\
\hline AA & $213(55.5)$ & $220(57.3)$ & 1.00 & 0.646 & 0.375 \\
\hline$A C$ & $143(37.2)$ & $137(35.7)$ & $1.05(0.78-1.42)$ & & \\
\hline CC & $28(7.3)$ & $27(7.0)$ & $1.04(0.59-1.83)$ & & \\
\hline \multicolumn{6}{|c|}{ RAG1: rs2227973 (R820K) } \\
\hline GG & 129 (33.6) & $134(34.9)$ & 1.00 & 1.000 & 0.586 \\
\hline GA & $200(52.1)$ & $190(49.5)$ & $0.96(0.70-1.30)$ & & \\
\hline $\mathrm{AA}$ & $55(14.3)$ & $60(15.6)$ & $0.83(0.54-1.29)$ & & \\
\hline \multicolumn{6}{|c|}{ XRCC5: rs1051685 (3' UTR) } \\
\hline $\mathrm{AA}$ & $313(81.5)$ & $326(84.9)$ & 1.00 & 0.232 & 0.808 \\
\hline$A G$ & $69(18.0)$ & $56(14.6)$ & $1.24(0.84-1.82)$ & & \\
\hline GG & $2(0.5)$ & $2(0.5)$ & $1.00(0.37-2.68)$ & & \\
\hline \multicolumn{6}{|c|}{ LIG4: rs1805388 (T9l) } \\
\hline $\mathrm{CC}$ & $163(42.4)$ & $222(57.8)$ & 1.00 & $<0.001$ & 0.659 \\
\hline $\mathrm{CT}$ & $172(44.8)$ & $142(37.0)$ & $1.62(1.20-2.18)$ & & \\
\hline$\pi$ & $49(12.8)$ & $20(5.2)$ & $3.27(1.87-5.71)$ & & \\
\hline \multicolumn{6}{|c|}{ XRCC4: rs 1805377 (Splice Site) } \\
\hline $\mathrm{AA}$ & $179(46.6)$ & $195(50.8)$ & 1.00 & 0.030 & 0.454 \\
\hline$A G$ & $143(37.2)$ & $153(39.8)$ & $0.96(0.71-1.30)$ & & \\
\hline GG & $62(16.2)$ & $36(9.4)$ & $1.77(1.12-2.80)$ & & \\
\hline \multicolumn{6}{|c|}{ ATM: rs189037 (-111G/A) } \\
\hline GG & $140(36.5)$ & $125(32.5)$ & 1.00 & 0.487 & 0.070 \\
\hline GA & $186(48.4)$ & $203(52.9)$ & $0.78(0.57-1.07)$ & & \\
\hline AA & $58(15.1)$ & $56(14.6)$ & $0.88(0.57-1.37)$ & & \\
\hline
\end{tabular}

${ }^{a}$ Adjusted for age, gender, smoking and drinking status.

${ }^{b}$ False Discovery Rate (FDR) corrected P-value.

$P<0.05$ for bold significances. 
Table 4 Risk of glioma associated with genotypes by smoking status

\begin{tabular}{|c|c|c|c|c|c|}
\hline Genotype & Smoking & Cases, $\mathrm{n}(\%)$ & Controls, $\mathrm{n}(\%)$ & OR $(95 \% \mathrm{Cl})^{\mathrm{a}}$ & $P_{\text {interaction }}{ }^{\mathrm{b}}$ \\
\hline \multicolumn{6}{|c|}{ LIG4: rs1805388 } \\
\hline CC & No & 107 (27.9) & $122(31.8)$ & 1.00 & \multirow[t]{4}{*}{$0.013 / 0.046$} \\
\hline $\mathrm{CT} / \mathrm{TT}$ & No & $121(31.5)$ & $96(25.0)$ & $1.39(0.96-2.01)$ & \\
\hline CC & Yes & $56(14.6)$ & $100(26.0)$ & $0.62(0.41-0.94)$ & \\
\hline $\mathrm{CT} / \mathrm{TT}$ & Yes & $100(26.0)$ & 66 (17.2) & $1.67(1.11-2.50)$ & \\
\hline \multicolumn{6}{|c|}{ XRCC4: rs 1805377} \\
\hline AA & No & $120(31.2)$ & $117(30.5)$ & 1.00 & \multirow[t]{4}{*}{$0.536 / 0.886$} \\
\hline $\mathrm{AG} / \mathrm{GG}$ & No & $108(28.1)$ & $101(26.3)$ & $0.99(0.68-1.44)$ & \\
\hline AA & Yes & 59 (15.4) & $78(20.3)$ & $0.70(0.46-1.07)$ & \\
\hline $\mathrm{AG} / \mathrm{GG}$ & Yes & $97(25.3)$ & $88(22.9)$ & $1.02(0.69-1.50)$ & \\
\hline
\end{tabular}

${ }^{\mathrm{a}}$ Adjusted for age, gender and drinking status.

${ }^{b} P$ for additive interaction/ $P$ for multiplicative interaction.

null mice can develop medulloblastoma [32]. Consistent with this notion, $X R C C 4 / p 53$ doubly deficient in nestinexpressing neuronal progenitor cells can lead to early onset of neuronally differentiated medulloblastomas [33]. Significant down-regulation of XRCC4 was found in grade II, III, IV of astrocytoma compared to normal brain tissues and decreased expression of XRCC4 was significantly associated with a poor prognosis $(P<0.05)$ [34]. These studies raise the possibility that decreased LIG4 or XRCC4 activity plays a role in human carcinogenesis.

Since tobacco is a well-confirmed inducer of DNA damage, in particular DSBs [35], we performed stratified analysis to estimate the interaction between the genotypes and smoking status. As shown in Table 4, LIG4 rs1805388 were associated with an increased risk of gliomas among smokers under a dominant model. Our data indicated the presence of an interaction between the NHEJ pathway genes and smoking status. In addition, smokers with less efficient DSB repair capacity may be more likely to develop gliomas.

Currently, the number of genome-wide association studies (GWAS) has been growing rapidly, leading to the discovery of many new variants associated with complex diseases. Two recent genome-wide association studies (GWAS) of risk of glioma in European populations did not identify an association between the XRCC4 rs1805377 and LIG4 rs1805388 polymorphisms and glioma risk [36,37]. There are several possible reasons for the contradictory findings between GWA studies and our present study. First, it might be due to genetic heterogeneity (both allelic and locus heterogeneity) in different ethnic populations or the different reporting criteria for a $P$ value. Second, the frequencies of XRCC4 rs1805377 and LIG4 rs1805388 polymorphisms and patterns of linkage disequilibrium (LD) are very different in two HapMap populations (CEU and CHB). Thirdly, it could be that the association of this variant may be population-specific and the interaction between genes and environmental factors vary in different human populations. Our results require confirmation in further GWA studies of gliomas in Chinese population.

Our study has several strengths. First, all tested SNPs were in Hardy-Weinberg equilibrium in controls. Second, in this study, a standardized genotyping approach was performed and quality control samples indicated a high degree of reproducibility of the genotyping results. Third, we were able to examine the association between the 2 SNPs and the risk of gliomas in a well-described and racially homogeneous population of the same ethnicity. Moreover, we use a pathway-based approach to estimate the combined effect of LIG4 and XRCC4 genes, which may provide enhanced risk assessment. Finally, we used a relatively comprehensive analysis of 10 polymorphisms in 7 candidate genes involved in DNA

Table 5 Interaction of LIG4 rs 1805388 and XRCC4 rs1805377 on risk of glioma

\begin{tabular}{|c|c|c|c|c|c|}
\hline LIG4 rs 1805388 & XRCC4 rs 1805377 & Cases, $\mathrm{n}(\%)$ & Controls, n(\%) & OR $(95 \% \mathrm{Cl})^{\mathrm{a}}$ & $P_{\text {interaction }}{ }^{\mathrm{b}}$ \\
\hline$\overline{C C}$ & AA & $94(24.5)$ & $107(27.9)$ & 1.00 & $0.005 / 0.009$ \\
\hline CC & $A G / G G$ & $69(18.0)$ & $115(29.9)$ & $0.73(0.48-1.09)$ & \\
\hline $\mathrm{CT} / \mathrm{TT}$ & AA & $85(22.1)$ & $88(22.9)$ & $1.17(0.78-1.75)$ & \\
\hline $\mathrm{CT} / \mathrm{TT}$ & $A G / G G$ & $136(35.4)$ & 74 (19.3) & $2.22(1.49-3.30)$ & \\
\hline
\end{tabular}

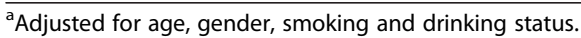

${ }^{\mathrm{b}} P$ for additive interaction/ $P$ for multiplicative interaction. 
double-strand break repair pathways. However, our current study has some limitations. First, we were not able to explore the exact biological mechanism of how XRCC4 rs1805377 and LIG4 rs1805388 polymorphisms affect the development of gliomas. Second, this study was a hospital-based case-control study; thus, selection bias in the present study may have led to spurious findings. However, the controls and cases were matched on age and sex, which may have minimized selection bias. Third, our findings need to be replicated in other independent studies. Fourth, we did not perform the stratified analysis by glioma grade due to the limited sample size. Therefore, large-scale studies and functional evaluation are warranted to replicate these findings in an independent population that is well-powered to performed stratified analysis by glioma grade.

\section{Conclusions}

In conclusion, of the 10 potential functional polymorphisms investigated here, we provide the first evidence that the XRCC4 rs1805377 (IVS7-1A>G, splice-site) and LIG4 rs1805388 (Ex2 +54C>T, Thr9Ile) polymorphisms contribute to the risk of developing gliomas, alone or in combination. This is also the first report to investigate the role of gene-gene and gene-environment interactions of these 10 potential functional SNPs of 7 major NHEJ and HR pathway genes in the development of gliomas. These findings may be helpful in improving our understanding of the etiology of gliomas. XRCC4 rs 1805377 and LIG4 rs1805388 polymorphisms may be useful susceptibility biomarkers for gliomas and aid in the development of diagnostic strategy to reduce the burden of gliomas. Future larger scale studies with ethnically diverse populations and functional evaluation are needed to confirm our findings.

\section{Competing interests}

The authors declare that they have no competing interests.

\section{Authors' contributions}

PZhao and PZou participated in collection of data and manuscript preparation. PZou and LZ performed the statistical analysis. WY, CK, YY and TJ provided the samples. PZhao participated in study design and critically revised the manuscript. PZhao and TJ participated in study design and manuscript preparation. All authors read and approved the final manuscript.

\section{Acknowledgments}

This work is supported by the National Natural Science Foundation of China (grant 30901534); the Jiangsu Province's Natural Science Foundation (Proj. no. BK2009444); and the Grant for the 135 Key Medical Project of Jiangsu Province (No. XK201117) and the Priority Academic Program Development of Jiangsu Higher Education Institutions.

\section{Author details}

${ }^{1}$ Department of Neurosurgery, the First Affiliated Hospital of Nanjing Medical University, Nanjing 210029, China. ${ }^{2}$ Department of Neurosurgery, Tiantan Hospital, Capital Medical University, Beijing 100050, China. ${ }^{3}$ Department of Neurosurgery, Tianjin Medical University General Hospital, Tianjin, 300052, China.
Received: 1 January 2013 Accepted: 3 May 2013

Published: 10 May 2013

\section{References}

1. Xue QC, Pu PY, Yang YS, Shen CH: A survey of 790 cases of astrocytoma. Clin Neurol Neurosurg 1990, 92(1):27-33.

2. Ohgaki $\mathrm{H}$, Kleihues P: Epidemiology and etiology of gliomas. Acta Neuropathol 2005, 109(1):93-108.

3. Louis DN, Ohgaki H, Wiestler OD, Cavenee WK, Burger PC, Jouvet A, Scheithauer BW, Kleihues P: The 2007 WHO classification of tumours of the central nervous system. Acta Neuropathol 2007, 114(2):97-109.

4. Liu Y, Shete S, Hosking FJ, Robertson LB, Bondy ML, Houlston RS: New insights into susceptibility to glioma. Arch Neurol 2010, 67(3):275-278.

5. Soulas-Sprauel P, Rivera-Munoz P, Malivert L, Le Guyader G, Abramowski V, Revy P, de Villartay JP: V(D)J and immunoglobulin class switch recombinations: a paradigm to study the regulation of DNA end-joining. Oncogene 2007, 26(56):7780-7791.

6. Khanna KK, Jackson SP: DNA double-strand breaks: signaling, repair and the cancer connection. Nat Genet 2001, 27(3):247-254.

7. Recuero-Checa MA, Dore AS, Arias-Palomo E, Rivera-Calzada A, Scheres SH, Maman JD, Pearl LH, Llorca O: Electron microscopy of Xrcc4 and the DNA ligase IV-Xrcc4 DNA repair complex. DNA Repair (Amst) 2009, 8(12):1380-1389.

8. Falck J, Coates J, Jackson SP: Conserved modes of recruitment of ATM, ATR and DNA-PKcs to sites of DNA damage. Nature 2005, 434(7033):605-611.

9. Stracker TH, Petrini JH: The MRE11 complex: starting from the ends. Nat Rev Mol Cell Biol 2011, 12(2):90-103.

10. Lieber MR: The mechanism of double-strand DNA break repair by the nonhomologous DNA end-joining pathway. Annu Rev Biochem 2010, 79:181-211

11. San Filippo J, Sung P, Klein H: Mechanism of eukaryotic homologous recombination. Annu Rev Biochem 2008, 77:229-257.

12. Liu Y, Shete S, Etzel CJ, Scheurer M, Alexiou G, Armstrong G, Tsavachidis $S$, Liang FW, Gilbert M, Aldape K, Armstrong T, Houlston R, Hosking F, Robertson L, Xiao Y, Wiencke J, Wrensch M, Andersson U, Melin BS, Bondy M: Polymorphisms of LIG4, BTBD2, HMGA2, and RTEL1 genes involved in the double-strand break repair pathway predict glioblastoma survival. J Clin Oncol 2010, 28(14):2467-2474.

13. Liu Y, Shete S, Wang LE, El-Zein R, Etzel CJ, Liang FW, Armstrong G, Tsavachidis S, Gilbert MR, Aldape KD, Xing J, Wu X, Wei Q, Bondy ML: Gamma-radiation sensitivity and polymorphisms in RAD51L1 modulate glioma risk. Carcinogenesis 2010, 31(10):1762-1769.

14. Benjamini Y, Hochberg Y: Controlling the false discovery rate: a practical and powerful approach to multiple testing. Journal of the Royal Statistical Society Series B (Methodological) 1995, 289-300.

15. Grawunder U, Zimmer D, Leiber MR: DNA ligase IV binds to XRCC4 via a motif located between rather than within its BRCT domains. Curr Biol 1998, 8(15):873-876.

16. Girard PM, Kysela B, Harer CJ, Doherty AJ, Jeggo PA: Analysis of DNA ligase IV mutations found in LIG4 syndrome patients: the impact of two linked polymorphisms. Hum Mol Genet 2004, 13(20):2369-2376.

17. O'Driscoll M, Cerosaletti KM, Girard PM, Dai Y, Stumm M, Kysela B, Hirsch B, Gennery A, Palmer SE, Seidel J, Gatti RA, Varon R, Oettinger MA, Neitzel H, Jeggo PA, Concannon P: DNA ligase IV mutations identified in patients exhibiting developmental delay and immunodeficiency. Mol Cell 2001, 8(6):1175-1185.

18. Dore AS, Furnham N, Davies OR, Sibanda BL, Chirgadze DY, Jackson SP, Pellegrini L, Blundell TL: Structure of an Xrcc4-DNA ligase IV yeast ortholog complex reveals a novel BRCT interaction mode. DNA Repair (Amst) 2006, 5(3):362-368.

19. Yurchenko V, Xue Z, Sadofsky MJ: SUMO modification of human XRCC4 regulates its localization and function in DNA double-strand break repair. Mol Cell Biol 2006, 26(5):1786-1794.

20. Sibanda BL, Critchlow SE, Begun J, Pei XY, Jackson SP, Blundell TL, Pellegrini L: Crystal structure of an Xrcc4-DNA ligase IV complex. Nat Struct Biol 2001, 8(12):1015-1019.

21. Wu PY, Frit P, Meesala S, Dauvillier S, Modesti M, Andres SN, Huang Y, Sekiguchi J, Calsou P, Salles B, Junop MS: Structural and functional interaction between the human DNA repair proteins DNA ligase IV and XRCC4. Mol Cell Biol 2009, 29(11):3163-3172.

22. Tseng RC, Hsieh FJ, Shih CM, Hsu HS, Chen CY, Wang YC: Lung cancer susceptibility and prognosis associated with polymorphisms in the 
nonhomologous end-joining pathway genes: a multiple genotypephenotype study. Cancer 2009, 115(13):2939-2948.

23. Abe T, Ishiai M, Hosono Y, Yoshimura A, Tada S, Adachi N, Koyama H, Takata M, Takeda S, Enomoto T, Seki M: KU70/80, DNA-PKcs, and Artemis are essential for the rapid induction of apoptosis after massive DSB formation. Cell Signal 2008, 20(11):1978-1985.

24. Mahaney BL, Meek K, Lees-Miller SP: Repair of ionizing radiation-induced DNA double-strand breaks by non-homologous end-joining. Biochem J 2009, 417(3):639-650.

25. Frank KM, Sekiguchi JM, Seidl K, Swat W, Rathbun GA, Cheng HL, Davidson L, Kangaloo L, Alt FW: Late embryonic lethality and impaired V(D)J recombination in mice lacking DNA ligase IV. Nature 1998, 396(6707):173-177.

26. Gao Y, Sun Y, Frank KM, Dikkes P, Fujiwara Y, Seidl K, Sekiguchi JM, Rathbun GA, Swat W, Wang J, Bronson RT, Malynn BA, Bryans M, Zhu C, Chaudhuri J, Davidson L, Ferrini R, Stamato T, Orkin SH, Greenberg ME, Alt FW: A critical role for DNA end-joining proteins in both lymphogenesis and neurogenesis. Cell 1998, 95(7):891-902.

27. Kesari S, Advani SJ, Lawson JD, Kahle KT, Ng K, Carter B, Chen CC: DNA damage response and repair: insights into strategies for radiation sensitization of gliomas. Future Oncol 2011, 7(11):1335-1346.

28. Gao Y, Ferguson DO, Xie W, Manis JP, Sekiguchi J, Frank KM, Chaudhuri J, Horner J, DePinho RA, Alt FW: Interplay of p53 and DNA-repair protein XRCC4 in tumorigenesis, genomic stability and development. Nature 2000, 404(6780):897-900.

29. Frank KM, Sharpless NE, Gao Y, Sekiguchi JM, Ferguson DO, Zhu C, Manis JP, Horner J, DePinho RA, Alt FW: DNA ligase IV deficiency in mice leads to defective neurogenesis and embryonic lethality via the p53 pathway. Mol Cell 2000, 5(6):993-1002.

30. Nijnik A, Dawson S, Crockford TL, Woodbine L, Visetnoi S, Bennett S, Jones M, Turner GD, Jeggo PA, Goodnow CC, Cornall RJ: Impaired lymphocyte development and antibody class switching and increased malignancy in a murine model of DNA ligase IV syndrome. J Clin Invest 2009, 119(6):1696-1705.

31. Sharpless NE, Ferguson DO, O'Hagan RC, Castrillon DH, Lee C, Farazi PA, Alson S, Fleming J, Morton CC, Frank K, Chin L, Alt FW, DePinho RA: Impaired nonhomologous end-joining provokes soft tissue sarcomas harboring chromosomal translocations, amplifications, and deletions. Mol Cell 2001, 8(6):1187-1196.

32. Lee Y, McKinnon PJ: DNA ligase IV suppresses medulloblastoma formation. Cancer Res 2002, 62(22):6395-6399.

33. Yan CT, Kaushal D, Murphy M, Zhang Y, Datta A, Chen C, Monroe B, Mostoslavsky G, Coakley K, Gao Y, Mills KD, Fazeli AP, Tepsuporn S, Hall G, Mulligan R, Fox E, Bronson R, De Girolami U, Lee C, Alt FW: XRCC4 suppresses medulloblastomas with recurrent translocations in p53-deficient mice. Proc Natl Acad Sci USA 2006, 103(19):7378-7383.

34. Jiang Z, Hu J, Li X, Jiang Y, Zhou W, Lu D: Expression analyses of 27 DNA repair genes in astrocytoma by TaqMan low-density array. Neurosci Lett 2006, 409(2):112-117.

35. Albino AP, Huang $X$, Jorgensen ED, Gietl D, Traganos F, Darzynkiewicz Z: Induction of DNA double-strand breaks in A549 and normal human pulmonary epithelial cells by cigarette smoke is mediated by free radicals. Int J Oncol 2006, 28(6):1491-1505

36. Shete S, Hosking FJ, Robertson LB, Dobbins SE, Sanson M, Malmer B, Simon M, Marie Y, Boisselier B, Delattre JY, Hoang-Xuan K, El Hallani S, Idbaih A, Zelenika D, Andersson U, Henriksson R, Bergenheim AT, Feychting M, Lonn S, Ahlbom A, Schramm J, Linnebank M, Hemminki K, Kumar R, Hepworth SJ, Price A, Armstrong G, Liu Y, Gu X, Yu R, et al: Genome-wide association study identifies five susceptibility loci for glioma. Nat Genet 2009, 41(8):899-904.

37. Wrensch M, Jenkins RB, Chang JS, Yeh RF, Xiao Y, Decker PA, Ballman KV, Berger M, Buckner JC, Chang S, Giannini C, Halder C, Kollmeyer TM, Kosel ML, LaChance DH, McCoy L, O'Neill BP, Patoka J, Pico AR, Prados M, Quesenberry C, Rice T, Rynearson AL, Smirnov I, Tihan T, Wiemels J, Yang P, Wiencke JK: Variants in the CDKN2B and RTEL1 regions are associated with high-grade glioma susceptibility. Nat Genet 2009, 41(8):905-908.

doi:10.1186/1471-2407-13-234

Cite this article as: Zhao et al: Genetic polymorphisms of DNA doublestrand break repair pathway genes and glioma susceptibility. BMC Cancer 2013 13:234.

\section{Submit your next manuscript to BioMed Central and take full advantage of:}

- Convenient online submission

- Thorough peer review

- No space constraints or color figure charges

- Immediate publication on acceptance

- Inclusion in PubMed, CAS, Scopus and Google Scholar

- Research which is freely available for redistribution

Submit your manuscript at www.biomedcentral.com/submit
( Biomed Central 